International Journal of Business Management and Economic Review

Vol. 2, No. 04; 2019

ISSN: 2581-4664

\title{
THE ROLE OF INTERNAL SAVINGS AND LENDING COMMUNITIES (SILC)IN ENHANCINGHOUSEHOLD'S LIVELIHOODSIN IGEMBE NORTH SUB COUNTY, KENYA
}

\author{
Florence KaumiKirimi, MSc \\ Department of Agricultural economics and Extension, University of Embu, P.O BOX 6-60100 Embu, Kenya \\ Lucy Karega Njeru, PhD \\ Department of Agricultural Economics, University of Nairobi,P.O BOX 29053-00625 Nairobi, Kenya \\ Joseph M'eruakiM'uthari, MDS \\ Department of Development Studies, St Pauls' University, Private Bag-00217 Limuru, Kenya
}

http://doi.org/10.35409/IJBMER.2019.2404

\begin{abstract}
Microfinance is one of the programs used for community social transformation in Kenya. Microfinance empowers people to work on their own thereby promoting poverty reduction. This study analysed the role of Internal Savings and Lending Communities (SILC) on enhancement of livelihoods among households in Igembe North Sub County. A descriptive survey was used to collect data from 315 randomly selected SILC members and 30 SILC officials in the SubCounty. Content validity of the questionnaire and interview guide was ascertained by development experts while reliability coefficients were $0.83 \alpha$ and $0.72 \alpha$ respectively. Focus group discussions with 30 groups were conducted to solicit relevant information. The level of community participation in SILC Group activities was high with 99\% participation and the level of household livelihood enhancement and improvement was evident with $97 \%$ agreeing that they had made a good improvement to their household livelihood due to their association with SILC activities. The improvement varied from farming through purchase of household assets to education and health in general. The government, development practitioners, policy makers and other actors should enhance improved livelihood and hence community transformation through SILC and other development programmes.
\end{abstract}

Keyword:Enhancement, empowerment, Household, Saving, Lending,

\section{INTRODUCTION}

Empowerment is major concept in development debates and world practice that is applicable at various levels of human development (Roodman, 2012); Wallenstein, 2006). Kasmel and Tanggaard (2011) underscored empowerment as the main subject of quality of life debates and is referred as increased abilities of individuals to engage in and make institutions which affect their lives contributing to reduction of inequality among community members (Hurst, 2007). Empowerment programs often have been effectively employed not only in handling health inequalities as revealed by Wilkinson and Pickett (2009); Stuckler et al., (2010) but also in prevention of majority of problems related to health and social aspects of life, such as damages, drug abuses and also for realization of social capital (Janssens, 2010; Andersen et al., 2011). 
International Journal of Business Management and Economic Review

Vol. 2, No. 04; 2019

ISSN: 2581-4664

Microfinance is one of the empowerment programs especially in the developing world. It empower people to work on their own, thereby eradicating poverty while avoiding dependency and enables community members to easily access credit facilities without collateral (Daley (2009; World Bank, 2013). Christabell (2009) confirmed that microfinance in itself does not lead to empowerment but, instead acts as catalysts to accelerate the beneficiaries to act in a way which is socially accepted. This is particularly with regards to gender related perspectives. According to Islam (2007), microfinance assists to enhance consumption for the poorer persons even though the impact may not be significant. The study was carried out in Igembe North Sub County which is categorized as a semi-arid agricultural region. The Sub County is dominated by SILC group activities covering the entire region. Due to high unemployment rate, low incomes and dense population, changing output and input prices and dependency on weather, agriculture is affected negatively (Ngore, 2010). Although the region is the main producer of miraa (Khat) that injects more than twenty billion shillings annually to the Kenyan economy, it is ironically ranked among the areas with the highest level of poverty, child malnutrition and illiteracy in the country (Ngoreet al., 2011). Savings and Internal Lending Communities (SILC) was initiated to change the trend and promote the savings and lending culture. This constitutes self-selected members, who form a group and raise contributions in form of savings that is pulled together to create a loan capital. The capital is then utilized by the group members to lend as loan that is paid back with interest.

The extent of participation in micro financial programs is when demand and supply of the services offered are equal. Individuals may decide to take part in this program depending on microfinance's services, individuals' needs and preference. According to Bauchet and Morduch (2010), the degree of participation in any given community will give useful information about the community's interest and may reveal the higher demand for better services. Some people may freelyjoin these micro finance institutions and work with them, while others may opt not to participate. Although, microfinance has numerous successes in expanding financial services to the poor, it often faces challenges when targeting those poor people in different communities (Bauer, Julie \& Jonathan, 2008).

Participation in microfinance can be measured based on aggregate approximation that is got from administrative records in various institutions. For instance, when you take the total number of customer of a certain financial lender and divides it with the total population in that specific area, it gives important rate of participation of people in that financial institution (Honohan, 2010). Measurement can also be obtained from general household surveys such as the World Bank's living standards measurement surveys. This type of measurement usually gives accurate information because people give information through either questionnaires or interviews that provide data on current, past and even future occurrences(Karlanet al., 2010).

Microfinance can change household's assets and use of these assets in coping with the world's vulnerability. A study by Ayertey (2008) showed that micro finances can lead to improvement of household's quality of lives. Self-esteem is also enhanced besides enabling people have different strategies of coping with poverty. Microfinance services also can impact positively in education and health of a society and especially at household levels (Wright, 2000). According to 
International Journal of Business Management and Economic Review

Vol. 2, No. 04; 2019

ISSN: 2581-4664

Honohan, (2010), microfinance could help in improving physical assets such as housing, improved livestock, land, equipment and tools needed for farming as well as other facilities.

SILC program in the study area was introduced with the aim of empowering the community. The participants are able to access loans conveniently and cost effectively thereby enhancing themselves and fulfilling several requirements that were difficult prior to SILC introduction. Ayertey (2008) confirmed that SILC is awakening the reality on gender issues, in that some women have their place in the society and own properties like men unlike before when assets were perceived to be owned by men. However, despite the SILC programme in the region, the level of poverty, illiteracy and malnutrition is quite on the increase. It is against this background that the study analysed the role of SILCin enhancing and improving development of households as well as the levelof participation in the SILC programmes in Igembe North Sub County.

\section{STATEMENT OF THE PROBLEM}

SILC was introduced in Igembe North Sub County in 2010 in attempt of minimizing problems facedin the Sub-County. Since its inception, the programme has progressed well with the concept being appreciated and widely sweeping across the entire Sub-County and its environs. The programme constitute 500 groups of 30 members each which are largely dominated by women. Nevertheless, a few men have joined SILC after witnessing the improvement gained by the members. However, the area is known to have people whose saving levels are very low, with high illiteracy and malnutrition for the children. The role played by SILC in the region to improve and enhance the livelihood and raise the standard of living for the households is poorly documented and understood, which make it difficult for Kenyan leaders and their development partners to formulate innovative strategies for promoting effective participation in the SILC programmes in the Sub County. This study provided the missing information, which can be used to make informed decision on how to improve and enhance livelihoods through greater participation in SILC and other microfinance programmes in Kenya.

\section{PURPOSE AND OBJECTIVES OF THE STUDY}

The study sought to carry out an analysis of the role (SILC) in enhancing household's livelihood in Igembe North Sub County.

\section{OBJECTIVES OF THE STUDY WERE:-}

- To examine the level of community participation in SILC activities in Igembe North Sub-County.

- To explore the extent in which SILC promoted household's livelihoods in Igembe North Sub- County.

\section{METHODOLOGY OF RESEARCH}

The study used a descriptive survey design to collect data from 314 SILC randomly selected SILC members and 30 SILC officials. Thirty focus group discussions were conducted. Nyaga (2010) asserts that descriptive research concentrates more on conditions which have already existed, practices which are held, and processes and trends that are on-going. Descriptive survey in research therefore, while simple in design and execution can yield important information 


\section{International Journal of Business Management and Economic Review}

Vol. 2, No. 04; 2019

ISSN: 2581-4664

about a phenomenon. Kothari (2008) contends that surveys are excellent vehicles for collecting original data for the purpose of studying the attitudes and orientations of a very large population.

\section{INSTRUMENT AND DATA COLLECTION PROCEDURES}

Based on the objectives of the study, a self-administered questionnaire developed by the researcher with open and closed-ended items was used for SILC members and an interview guide for the SILC officials. The questionnaire contained information on the assessment of the role played by SILC in community empowerment in Igembe North Sub-County. The questionnaires' content validity was ascertained by five development experts while reliability was ascertained through a pilot test involving 30 SILC members from Igembe South Sub County which has similar characteristics as Igembe North Sub County. This indicated that the questionnaire and interview guide had reliability coefficients of $0.83 \alpha$ and $0.72 \alpha$ respectively, which were above the 0.70 minimum acceptable threshold at a significance level of 0.05 set a priori.

\section{DATA ANALYSIS}

Data was analysed using qualitative and quantitative methods. Qualitative data was evaluated, classified into categorized themes based on the objectives of the study and then coded. Analysis of qualitative data was an on-going process where emerging trends were categorized based on research questions. Quantitative data were coded and analysed using the Statistical Package for Social Sciences (SPSS). Frequency tables and percentages summarized and presented the quantitative data.

\section{RESULTS OF RESEARCH}

\section{Table 1 Gender Representation}

\begin{tabular}{|lrr|}
\hline Gender & Frequency & Per cent \\
\hline Male & 21 & 6.7 \\
Female & 292 & 93.3 \\
\hline Total & 313 & 100.0 \\
\hline
\end{tabular}

The household engagement and participation in SILC activities in the study area is unique since its membership is dominated by majority (93.3\%) female while male members only represents $(6.7 \%)$ as outlined in table 1.

\section{Age of Respondents}

The age of respondents was important to determine the average age of members engaged in SILC activities in the Sub-County. The results are given in Table 2. 
International Journal of Business Management and Economic Review

Vol. 2, No. 04; 2019

ISSN: 2581-4664

Table 2 Age Categories of the Respondents

\begin{tabular}{|c|c|c|}
\hline Age categories (years) & Frequency & Per cent \\
\hline Below 18 & 2 & 0.6 \\
\hline $19-35$ & 134 & 42.7 \\
\hline $36-45$ & 94 & 30 \\
\hline $46-50$ & 71 & 22.6 \\
\hline Above 50 & 13 & 4.1 \\
\hline Total & 314 & 100.0 \\
\hline
\end{tabular}

Majority of the respondents (42.7\%) were between the age of 19 and 35 years, with only (4.1\%) respondent aged above 50 years. The other age categories were 36 to $45(30 \%)$ and 46 to 50 (22.6\%). This shows that majority of the respondents (72.7\%) engaged in SILC activities are young members aged between 19 and 45 years.

\section{Academic Level attained by the Respondents}

The respondents were required to indicate the level of education they attained. The responses and their frequency distributions are given in Table 3.

Table 3 Academic Qualification of the Respondents

\begin{tabular}{|lrr|}
\hline Formal academic level & Frequency & Per cent \\
\hline Never went to School & 76 & 24.2 \\
Primary & 206 & 65.6 \\
Secondary & 29 & 9.2 \\
College (certificate) & 3 & 1 \\
University & 0 & 0 \\
\hline Total & 314 & 100.0 \\
\hline
\end{tabular}

Table 3 indicates majority of the respondents $(65.6 \%)$ had attained the primary level of education, while $(24.2 \%)$ had never gone to school. Only $(9.2 \%)$ had secondary level of education and (1\%) had college education. No single respondents had university education. This means that majority of the respondents were illiterate $(89.8 \%)$ having never gone to school or being a primary school dropout.

\section{Occupation of the Head of the Household}

The respondents were required to indicate their occupation and how they earned their living.

The responses and their frequency distributions are given in Table 4. 
International Journal of Business Management and Economic Review

Vol. 2, No. 04; 2019

ISSN: 2581-4664

Table 4Occupation of the Household Head

\begin{tabular}{|lrr|}
\hline & Frequency & Percentage \\
\hline Occupation & 256 & 84.4 \\
Busining & 43 & 13.7 \\
Employed & 6 & 1.9 \\
\hline Total & 314 & 100.0 \\
\hline
\end{tabular}

Source: Field Data, 2015

Table 4 indicates that majority of the households (84.4\%) were farmers, followed by (13.7\%)respondents who engaged in some form of business. Only (1.9\%) of the household head had formal employment.

\section{Approximate Incomes for the Household Head from their Occupation}

The respondents were required to indicate the approximate amount of income they earned from their occupation in a month. The responses are given in Table 5.

Table 5 Income of the Household Head

\begin{tabular}{|lrr|}
\hline Income source in Ksh & Frequency & Percentage \\
\hline Less than 5,000 & 232 & 73.9 \\
$5,000-9,000$ & 37 & 11.8 \\
$10,000-14,000$ & 34 & 10.8 \\
$15,000-19,000$ & 3 & 1 \\
Above 19,000 & 8 & 2.5 \\
\hline Total & 314 & 100.0 \\
\hline
\end{tabular}

The respondents were asked to state the approximate income they earn in a month from their occupation. The results are indicated in table 5 showing that majority (73.9\%) earned below ksh 5,000 , followed by $(11.8 \%)$ who earned between 5,000 and 9,000. This was closely followed by $(10.8 \%)$ households who earned between 10,000 and 14,000 and those who earned above ksh 19,000 were $(2.5 \%)$ with the least (1.0\%) who earned between 15,000 and 19,000. This shows that poverty is still a dominant issue in the study area despite the area being famous with SILC activities since majority of the members (73.9\%) survive on less than 5000 in a month and this agrees with the report by Islam (2007) who argued that microfinance like SILC assists to 
Vol. 2, No. 04; 2019

ISSN: 2581-4664

enhance consumption for the poorer persons even though, the impact is not significant. It is also in accordance with report by Ngoreet al., (2011) which confirmed that the region is the main producer of miraa that injects more than KES 20 billion annually to the economy, however, it is ironically ranked among the areas that record the highest level of poverty and illiteracy level in the County. Ngoreet al., (2011) further confirmed that miraa is the major source of income in Igembe North Sub County and many households depend on it for most of their livelihood needs. However, its recent ban in terms of sale and trade in most European markets has affected the community negatively in terms access to income therefore agreeing with the findings.

\section{Level of Household Participation in SILC}

Data in this section dealt with objective one which addressed the following research question:What is the level of community participation in SILC activities in Igembe North Sub- County?

Table 6 Level of Participation in SILC

\begin{tabular}{|lrr|}
\hline Participation & Frequency & Percentage \\
\hline Yes & 311 & 99 \\
No & 3 & 1 \\
\hline Total & 314 & 100.0 \\
\hline
\end{tabular}

The respondents were asked to state their level of participation in SILC groups and for how long they have been participation. The result is indicated in Table 6 showing that the vast majority of households (99\%) are active members of SILC activities. Only (1\%) of the respondents were not involved in SILC. This means that the level of participation is quite high in the study area since the entire Sub- County is covered with SILC.

\section{Table 7 Length of Membership in SILC}

\begin{tabular}{|lrr|}
\hline Length & Frequency & Percentage \\
\hline Less than I year & 96 & 30.5 \\
1 -2 years & 102 & 32.5 \\
More than 2 years & 116 & 37 \\
\hline Total & 314 & 100.0 \\
\hline
\end{tabular}

The respondents gave their length of stay in SILC groups. The results are indicate in Table 7indicating that majority of the of the respondents (37.0\%) had more than 2 years in SILC 
Vol. 2, No. 04; 2019

ISSN: 2581-4664

group activities, followed closely by between 1 and 2 years (32.5\%) and finally those who were less than a year old in SILC groups (30.5\%). This is in accordance with the study by Bauchet and Morduch (2010) who argued that the degree of participation in any given community empowerment program will give useful information about the community's interest and may reveal the higher demand for better services. It also agrees with Bauer, Julie \& Jonathan (2008) who contends that it is essential to properly understand participation in microfinance because it is not universal but differ from region to region. Some people may decide not to participate while others will easily agree to join these institutions. However the level of SILC participation in the study area was quit high as indicated in the results in table 7 , an indication that the community members are comfortable with benefits derived from SILC group innovations and initiatives.

\section{Household's Assets Improvement for SILC Member}

Data in this section dealt with the objective two of the study that addressed the following research question:-To what extent does SILC contribute to the households' livelihood in Igembe North Sub-County?

Figure 2 Ways of Improvement on Livelihood

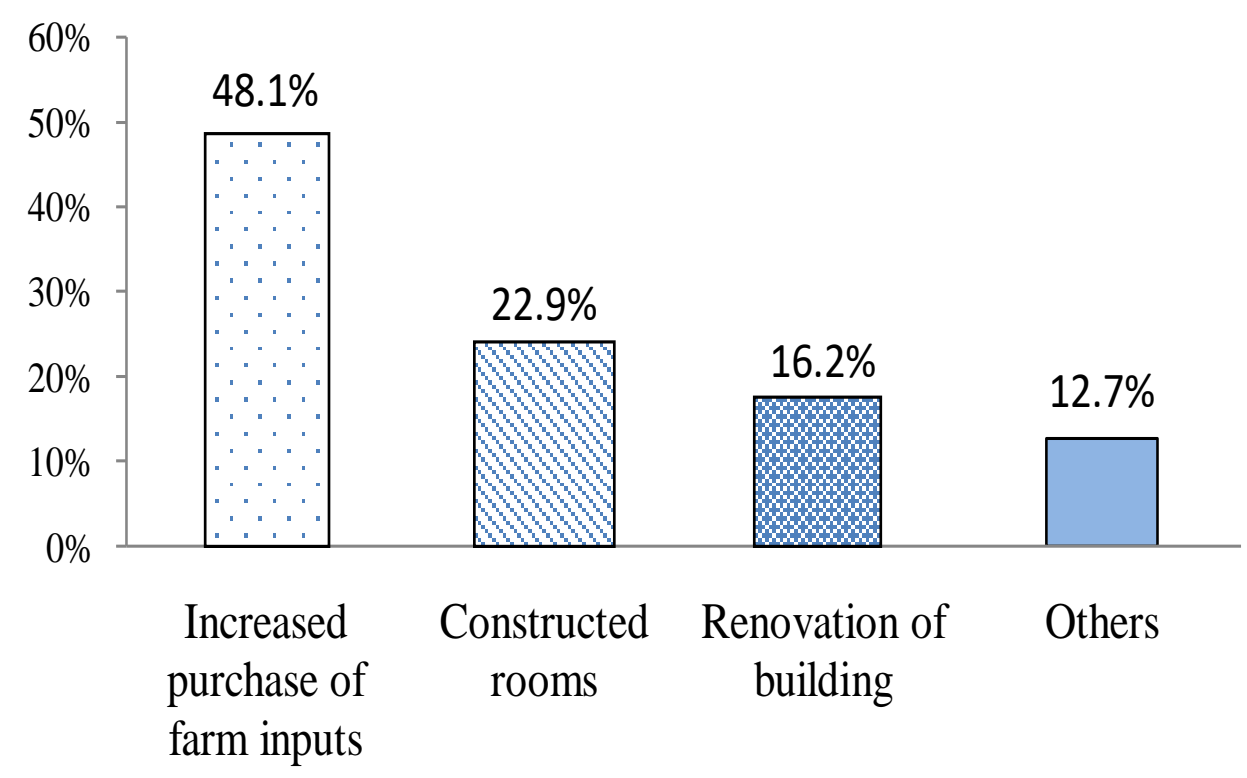

\section{Improvement categories}

The respondents were asked to state how they made recent improvement to their household assets following their association with SILC. The results are given in Figure 3 indicating that majority of the respondents (48.1\%) had improved their farm inputs, this was followed closely by $(23.0 \%)$ who had improved on house renovation. A few respondents $(16.2 \%)$ had renovated their buildings from the SILC groups. Only (12.7\%) had other improvements for instance purchase of kitchen utensils, purchase of poultry and rabbits for rearing, purchase of small water tanks for harvesting and storing water. This is in accordance with a study by Ayertey (2008) that 
Vol. 2, No. 04; 2019

ISSN: 2581-4664

showed that micro finances have led to improvement of Quality of lives of people. Self-esteem of the people is further enhanced besides enabling them to have different strategies of coping with poverty and thus they are able to live well. Ayertey (2008) further confirmed microfinance aids in improving physical assets such as increased in people's livestock, land and other facilities thus raising their standard of living agreeing with the findings of the study.

\section{Table 8 Areas more Improved due to SILC}

\begin{tabular}{|lrr|}
\hline Areas improved & Frequency & Percentages \\
\hline None & 4 & 1.3 \\
Health & 40 & 12.7 \\
Education & 255 & 81.2 \\
Confidence in decision making & 10 & 3.2 \\
Others & 5 & 1.6 \\
\hline Total & 314 & 100.0 \\
\hline
\end{tabular}

The respondents were asked to indicate other improvements from SILC groups. The results are given in Table 8 that shows that majority of the households (81.2\%) had improvement in educating their children through the SILC activities. This was followed by those who had improved in health (12.7\%) and only (3.2\%) had improvement on confidence and decision making due to SILC groups. A few respondents (1.4\%) had no improvement whosoever while only (1.6) had improvement in other aspects for example in acquiring livestock like cows, starting businesses, purchase of household water tanks and improving their level of sanitation and grooming. This is in line with Wright (2000) who confirmed that effects of microfinance are felt in education and health sectors of a society and especially at household levels. According to Wright (2000), microfinance has positive effects on education and health of members who participate in microfinance institution's saving and loaning. Microfinance also helps in improving physical assets such as increased in people's livestock, land and other facilities and majorly for those who engage in microfinance institutions' services.

\section{CONCLUSIONS}

1. The level of community participation in SILC Group activities is high as evidenced by (99\%) household in SILC programs with the duration of membership varying between less than 12 months to 2 years.

2. About (37\%) members confirmed to have been in SILC programme for over 2 years.

3. The level of household livelihood improvement was evident with majority (97.0\%) agreeing that they have made a good improvement to their household assets due to their association with SILC activities. The improvement varied from farming through purchase of household assets to education and health in general. 
International Journal of Business Management and Economic Review

Vol. 2, No. 04; 2019

ISSN: 2581-4664

\section{RECOMMENDATIONS}

1. The policy makers, leaders and other development players should come up with sustainable ways of ensuring community development through attracting more membership and participation in SILC groups in a bid to ensure more empowerment at the household level.

2. Increased capacity building for the community members through training and education as literacy skills leads acquisition of knowledge, information and confidence, which can lead to empowerment and make them demand for change thus the household livelihood will improve further.

3. The leaders need to support the SILC group's initiatives and strengthen them so that membership can increase particularly to attract male members as this is evidenced to be the dominant source of income for the households in the study area.

\section{RECOMMENDATION FOR FURTHER RESEARCH}

1. Other researchers should replicate this study to determine whether the situation is different in other areas, this would help them come up with a more comprehensive programme for enhancing community empowerment programs in Kenya.

2. Given that majority of the household had very high illiteracy levels, its influence on performance of SILC groups can be investigated further in the study area.

\section{REFERENCES}

Andersen, P. Jorgensen, S. \& Larsen, E. (2011). For the Sake of Health. Reflections on the Contemporary use of Social Capital and Empowerment in Danish health promotion policies. Soc. Theory Health 9, 87-107..

Ayertey, M. (2008). Microfinance and its Impact on Selected Districts in Eastern Region of Ghana. A Thesis Submitted to the Department of Economics for the Degree of MPhil, KNUST, Kumasi, Ghana.

Bauchet, J. \& Morduch, J. (2010). An Introduction to Impact Evaluations with Randomized Designs. Financial Access Initiative Framing Note.

Christabell, P. (2009). Women Empowerment through Capacity Building. The Role of Microfinance. Concept Publishing Company, New Delhi-India.

Daley, S. (2009). State of the Microcredit Summit Campaign Report. Washington, DC: Microcredit Summit Campaign.

Dupas, P. \& Jonathan, R. (2009). Savings Constraints and Microenterprise Development: Evidence from a Field Experiment in Kenya. NBER Working Paper 14693.

Honohan, P. (2010). Data On Microfinance And Access: Thinking About what is Available and what is needed, mimeo, Washington, D.C

Hurst, E. (2007). The Impact of Inequality on Personal Life Chances. Social Inequality, 6th ed.; Pearson: Boston, MA, USA, pp. 243-251.

Islam, A. (2007). Who Benefits from Microfinance? The Impact Evaluation of Large Scale Programs in Bangladesh, Working Paper.

Janssens, W. (2010). Women's Empowerment and the Creation of Social Capital in Indian Villages. World Dev. 38, 974-988.

Julie ,C. \& Jonathan, M. (2008). Behavioral Foundations of Microcredit: Experimental and 
International Journal of Business Management and Economic Review

Vol. 2, No. 04; 2019

ISSN: 2581-4664

Survey Evidence from Rural India. Institute of Economics Studies Working Papers

28/2008, Charles University in Prague.

Karlan, D., Morduch, J. \& Mullainathan, S. (2010). Take-up: Why Microfinance Take-Up Rates

Are Low $m d$ Why It Matters, The Financial Access Initiative, New York University,

Harvard, Yale and Innovations for Poverty Action.

Kasmel, N. \&Tanggaard, P. (2011). Evaluation of Changes in Individual Community-Related

Empowerment in Community Health Promotion Interventions in EstoniaInt J Environ Res

Public Health. vol8(6): 1772-1791.

Kothari, C. R. (2008). Research methodology: Methods and techniques, (pp. 1-56). New Delhi:

New Age International (P) Limited, Publishers (ISBN 10:81-224-1522-9).

Mjomba, E. (2011). Micro-finance and financial empowerment of women in Kenya. $\mathrm{PhD}$

Thesis, University of Nairobi. Unpublished.

Ngore, P. (2010). Evaluation of Factors Influencing Value Addition by ButcheryAgribusinesses in Igembe North District, Kenya, Master's Thesis, Egerton University.

Ngore, P. Mshenga, P. Owuor, G. \& Mutai, B. (2011). Socioeconomic Factors Influencing Meat

Value Addition by Rural Agribusinesses in Kenya, Current Research Journal of Social

Sciences 3(6): 453-464, 2011.

Nyaga, A. (2010). Factors Leading to Drop Out Among Female Students inSecondary Schools.

Runyenjes Division Of Embu East District, Kenya, Master's Thesis, Chuka University

College.

Roodman, D. (2012). Due Diligence: An Impertinent Inquiry into Micro-finance . Washington,

D.C: Center for Global Development, 2012.

Stuckler, D. Basu, S. Suhrcke, M. \& McKee, M. (2010). The Public Health Effect of Economic

Crisis and Alternative Policy Responses in Europe: An empirical analysis. The Lancet,374, 315-323.

Wallenstein, N. (2006). What is the Evidence on Effectiveness of Empowerment to Improve Health?: World Health Organization Regional Office for Europe (Health Evidence Network)

Wilkinson, R. \& Pickett, K. (2009). The Spirit Level: Why More Equal Societies Almost always do Better, Allen Lane: London, U.K

Wright, N. (2000). Microfinance Systems: Designing Quality Financial Services for the Poor, Zed Books Ltd. London \& New York, and the University Press Limited, Dhaka

World Bank. (2013). Finance for Growth, Policy Choices in a Volatile World, Oxford University Press and Washington, D.C. 